\title{
Angiotensin I Measurement
}

National Cancer Institute

\section{Source}

National Cancer Institute. Angiotensin I Measurement. NCI Thesaurus. Code C74844.

The determination of the amount of angiotensin I hormone present in a sample. 